diuretic phase with resolution of uraemia. An obvious renal vascular insult with severe hypotension was apparent on both occasions as a precipitating cause, Gram-negative septicaemia being proved for the initial attack and clinically suspect for the second. The inadvisability of the wound resuture being undertaken without institution of antibiotic therapy was apparent on retrospect, and the second severe collapse and subsequent renal failure highlights the nephrotoxicity of a Gram-negative bacteriaemia. In the first episode the time period from the onset of oliguria to the onset of spontaneous lowering of the urea level, which is a more reliable index of the severity of the course of acute renal failure than the period of oliguria (Niall, 1963), was 12 days, and in the second instance it was 20 days. Although the patient was in excellent health one yẹar later, residual impairment of renal function existed.

Case 2 illustrates even more strikingly the danger of bacteriaemia developing as a complication during the course of acute renal failure. When it was apparent that an operation during the diuretic phase of his acute renal failure was unavoidable because of the development of an acute abdominal emergency, the danger of precipitating a second episode was thought to be considerable, especially in view of our previous experience. Pre-operative hydration and blood replacement during operation were accordingly screened carefully, aided by determinations of blood volume. Antibiotic therapy was begun, although no previous evidence of infection existed, and a mannitol infusion given during the operation was continued thereafter for 24 hours. A transient post-operative oliguria with a rise in the urea level was noted, but a brisk diuresis then lowered the urea level again towards normal. However, the collapse due to Gram-negative septicaemia six days after operation, although treated early and vigorously, resulted in a second severe episode of oliguric renal failure requiring two haemodialyses. The respective times from onset of oliguria to fall in urea level were 13 days on the first and 11 days on the second occasion.

Gram-negative septicaemia, both as the origin and as a complication of acute renal failure, is a major cause of morbidity and mortality in most centres, and these two cases emphasize its hazards.

Recurrence of acute renal failure in the second patient was not prevented by antibiotic therapy and mannitol infusion, although mounting clinical and experimental evidence affords support for the protective effects of a mannitol-induced osmotic diuresis in renal failure from other causes (Barry et al., 1961).
The lack of protective effect of mannitol in a patient recovering from acute tubular necrosis may perhaps have been predicted from the failure of mannitol given during the previous cholecystectomy to prevent a short period of postoperative oliguria, although mannitol has been effective in reversing post-operative antidiuresis in patients with preoperative renal impairment due to a variety of diseases (Seitzman et al., 1963).

It is possible that additional protection may be provided by the use of dextran of low molecular weight (Rheomacrodex) in bacteriaemic shock, not by virtue of its diuretic effect, which is minor (Rabelo et al., 1962; Matheson et al., 1964), but perhaps by its action in improving the microcirculation in low-flow states (Gelin and Zederfeldt, 1960).

Finally, these patients afford opportunity for speculation on the pathogenesis of acute oliguric renal failure. Such instances of recurrerce of renal failure, with two episodes following each other so closely, appear to suggest a functional vascular aetiology rather than an organic tubular necrosis (Finckh, 1962).

\section{Summary}

Two patients, each having two separate episodes of acute renal failure, are recorded. The second attack on each occasion occurred during the recovering diuretic phase after a typical episode of acute oliguric renal failure. In the first patient recurrence of a Gram-negative septicaemia was responsible. The second patient developed a Gram-negative septicaemia during convalescence from post-traumatic acute renal failure.

These cases highlight the nephrotoxicity of Gram-negative septicaemia, and it is of interest that mannitol was found to be ineffective in preventing renal failure in the second patient.

I am grateful to Mr. C. Schneider for permission to publish the details of the second patient's illness.

\section{REFERENCES}

Barry, K. G., Cohen, A., and LeBlanc, P. (1961). Surgery, 50, 335. Bluemle, L. W., jun., Webster, G. D., and Elkinton, J. R. (1959). Arch. intern. Med., 104, 180.

Finckh, E. S. (1962). Lancet, 2, 330.

Gelin, L. E., and Zederfeldt, B. (1960). Acta chir. scand., 119, 168.

Gray, W. G., and North, J. D. K. (1960). Lancet, 1, 1169

Matheson, N. A., Irvin, T. T., and Hedley, A. J. (1964). Ibid., 2, 501

Niall, J. F. (1963). Med. F. Aust., 2, 740 .

Rabelo, A., Litwin, M. S., Brady, M. P., and Moore, F. D. (1962). Surg. Gynec. Obstet., 115, 657.

Seitzman, D. M., Mazze, R. I., Schwartz, F. D., and Barry, K. G. (1963). f. Urol. (Baltimore), 90, 139.

\title{
Primary Hyperparathyroidism Resembling Rickets of Late Onset
}

\author{
H. M. LLOYD,* D.M., PH.D., M.R.C.P. ; R. E. AITKEN,† F.R.C.S., F.R.A.C.S. ; T. M. FERRIER, $\ddagger$ M.B., M.R.A.C.P.
}

Brit. med. F., 1965, 2, 853-856

Primary hyperparathyroidism is rare in childhood and early adolescence, and may present special difficulties in diagnosis. Delay in treatment is dangerous, since children are prone to develop severe hypercalcaemia (Nolan, Hayles, and Woolner, 1960), and may suffer irreversible mental impairment (Anspach and Clifton, 1939 ; Harmon, 1956). Moreover, bone discase, if present, may cause rapidly progressive deformity resulting in prolonged or permanent incapacity.

* Reader in Medicine, Medical Professorial Unit (University of Queensland), Brisbane Hospital, Brisbane, Queensland, Australia. † Junior Surgeon, Brisbane Hospital, Brisbane, Queensland, Australia. ¥ Assistant Physician, Brisbane Hospital, Brisbane, Queensland, Australia.
Important aspects of primary hyperparathyroidism in childhood were encountered in the patient described in this report. The osseous manifestations were of unusual interest, comprising osteitis fibrosa cystica, osteosclerosis, and metaphysial changes simulating rickets. There was a neurological disturbance resembling chorea.

\section{Case Report}

A 14-year-old schoolboy was admitted to Brisbane Hospital on 18 February 1964. He had been well until two years previously, when his scholastic performance began to deteriorate and his cheer- 
ful personality changed to one of apathy. In August 1963 he started to grow more rapidly, and his height increased by 5 to $7 \mathrm{~cm}$. in the next six months. During this period he became knock-kneed and complained of weakness in his legs, which prevented him from walking more than $\frac{3}{4}$ mile $(1,200$ metres) at a time. He had no pain in his legs, and his only other symptoms were occasional sharp pains in the left side of his chest and anorexia in the mornings. There was no excessive thirst or polyuria ; nor were there any symptoms referable to the urinary

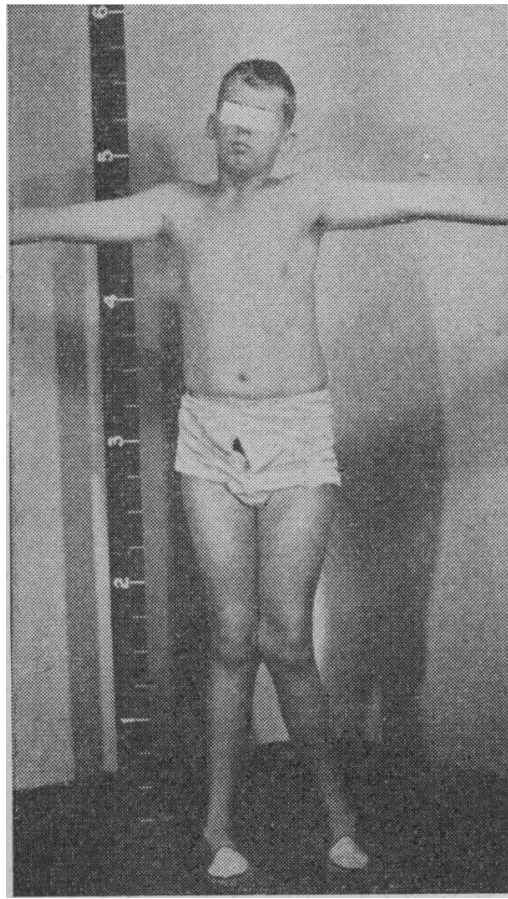
Fig. 1.-The patient, showing severe knock-knee. with inactive tendon reflexes, and a mild ataxic tremor in both upper limbs. His gait was laboured, largely because of the severe knockknee, with, in addition, waddling, high steppage, and circumduction of the feet.

\section{Investigations}

The results of the principal biochemical investigations are given in the Table. Other results were as follows: haemoglobin $13.2 \mathrm{~g} . /$ $100 \mathrm{ml}$.; serum amylase 100 Somogyi units $/ 100 \mathrm{ml}$; serum creatinine $1.3 \mathrm{mg} . / 100 \mathrm{ml}$; ; serum protein $7.2 \mathrm{~g} . / 100 \mathrm{ml}$. with normal electrophoretic pattern ; serum uric acid $9.7 \mathrm{mg} . / 100 \mathrm{ml}$; serum protein-bound iodine $6 \mu \mathrm{g} . / 100 \mathrm{ml}$.; serum electrolytes: sodium 142 , potassium 5.2 , chloride $104, \mathrm{CO}_{2}$-combining power $21.4 \mathrm{mEq} /$ litre. Microscopical examination of the urine (centrifuge deposit) revealed 20 leucocytes and 10 red cells per high-power field.

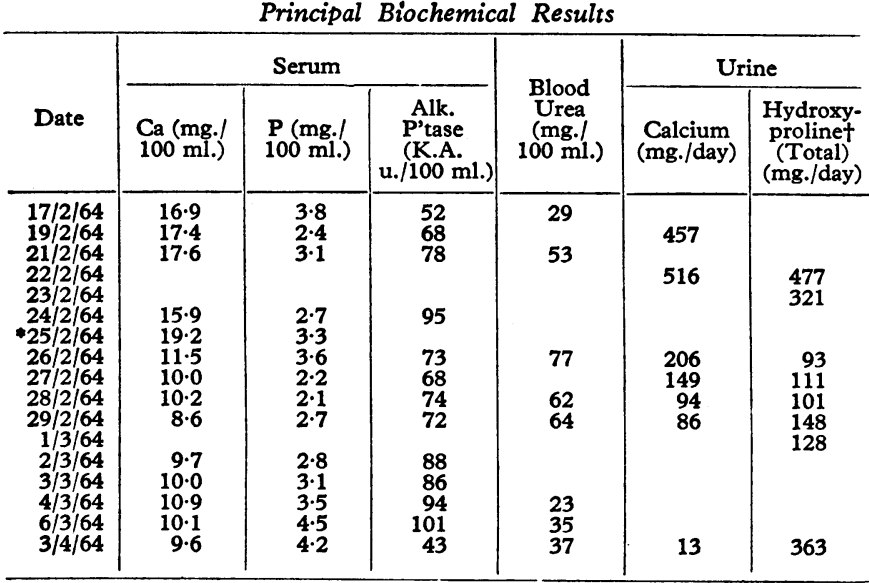

* Day of operation. + Method of Prockop and Udenfriend (1960).
Radiographs revealed subperiosteal erosions in the fingers, in the proximal metaphyses of the humeri and tibiae, and in the distal metaphyses of the radii. There was a cyst-like lesion in the head of the left fifth metacarpal. The anterior ends of the lower ribs were expanded and cupped (Fig. 2). The epiphysial plates at the shoulders, ankles, and hips were enlarged, irregular, and poorly defined (Fig. 3), but they were normal at the wrists. At the knees the epiphysial plates appeared nearly normal, but in the metaphyses of both femurs, just proximal to the epiphysial plate, a radiolucent zone extended about $2 \mathrm{~cm}$. across the width of the bone (Fig. 4). Bone of increased radiopacity was present in the proximal metaphyses of the tibiae (Fig. 4), and in the upper and lower parts of the bodies of the lower thoracic and lumbar vertebrae (Fig. 5). Skull $x$-ray examination showed no definite abnormality, and the pituitary fossa was not eroded or enlarged. The lamina dura was intact in some sites and deficient in others. Radiographs of the renal areas showed no renal calculi or nephrocalcinosis.

A bone biopsy specimen (iliac crest) revealed the following changes: gross marrow fibrosis of a cellular type ; increased osteoblastic activity ; numerous osteoclasts, some actively resorbing bone, others lying in the fibrous tissue; trabeculae showing internal irregularity.

Two electroencephalograms, recorded on different occasions, showed bilaterally symmetrical 9 c.p.s., 50 microvolt alpha rhythm with almost continuous synchronous polymorphic 4-5 c.p.s. activity at amplitudes up to 50 microvolts occurring extensively over the temporal lobes. An electrocardiogram showed some shortening of the Q-T interval consistent with hypercalcaemia.

At operation on 25 February a parathyroid adenoma weighing $1.5 \mathrm{~g}$. was removed from the left inferior position. It was composed of chief cells with some transitional and "water-clear" cells. The post-operative course was uneventful, and despite the rapid fall in serum calcium (see Table) tetany did not occur. Within two weeks of operation he was less apathetic and was taking more interest in his surroundings. The neurological signs gradually remitted. The subperiosteal erosions and the bone "cyst" had healed within three

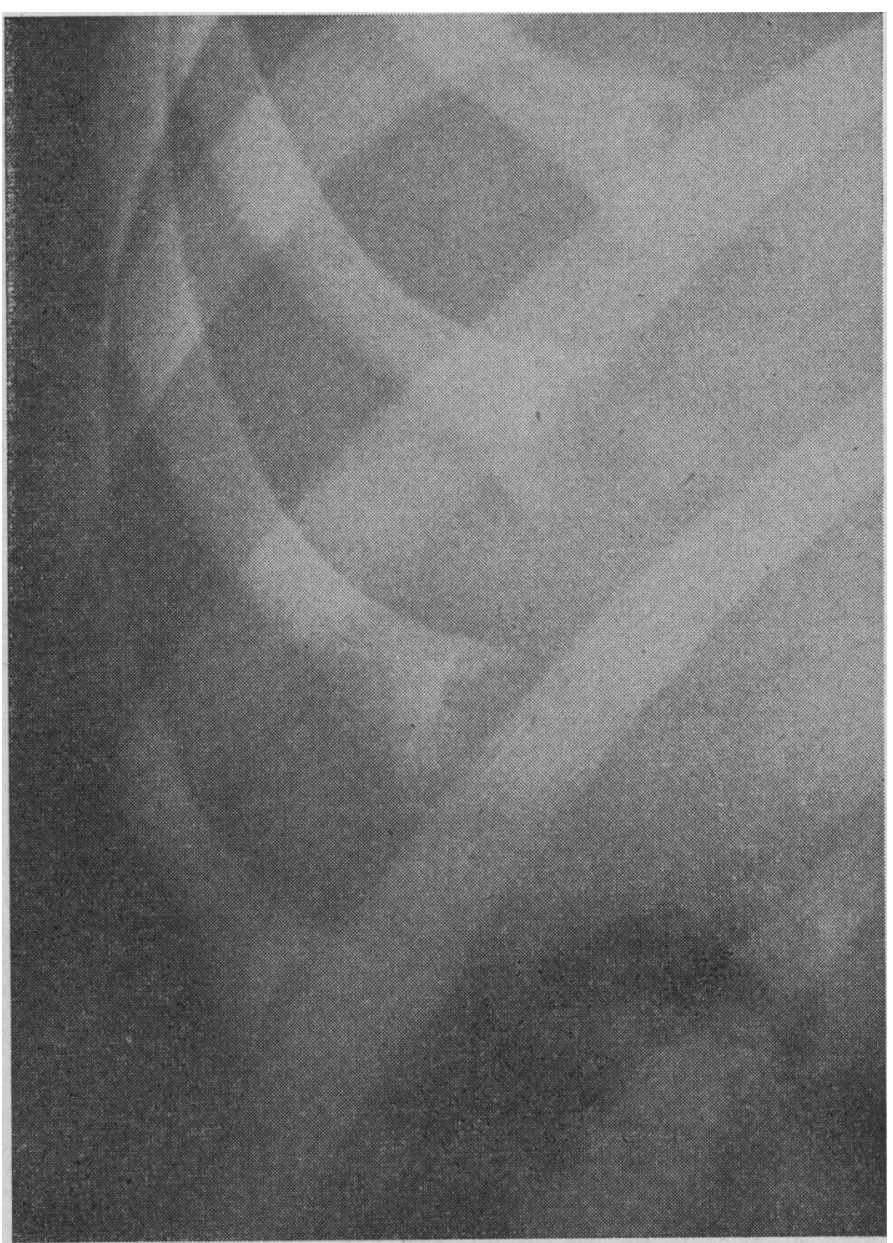

FIG. 2.-Expanded, cupped anterior ends of lower ribs. 
months of operation. The ankle metaphyses were nearly normal within one month, but at the hip healing was less rapid. The osteosclerotic changes and beading of the ribs were no longer present six months after operation. He continued to grow in height, with

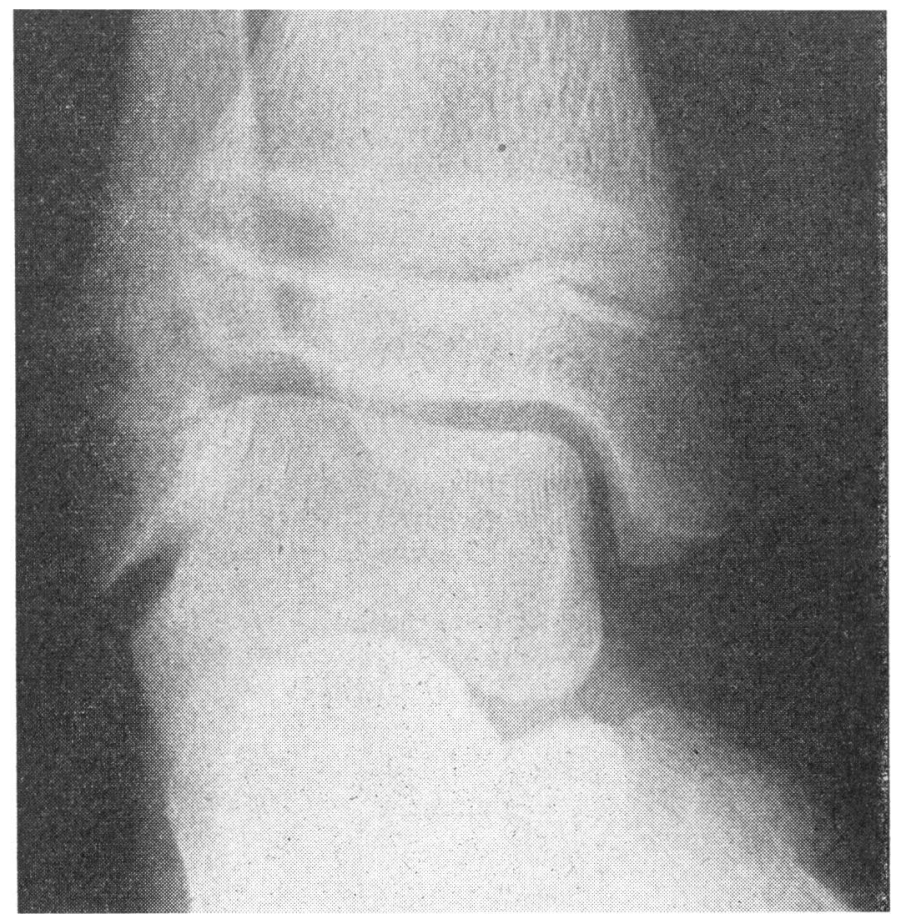

FIG. 3.-Enlarged, irregular, poorly defined epiphysial plates at the ankle.

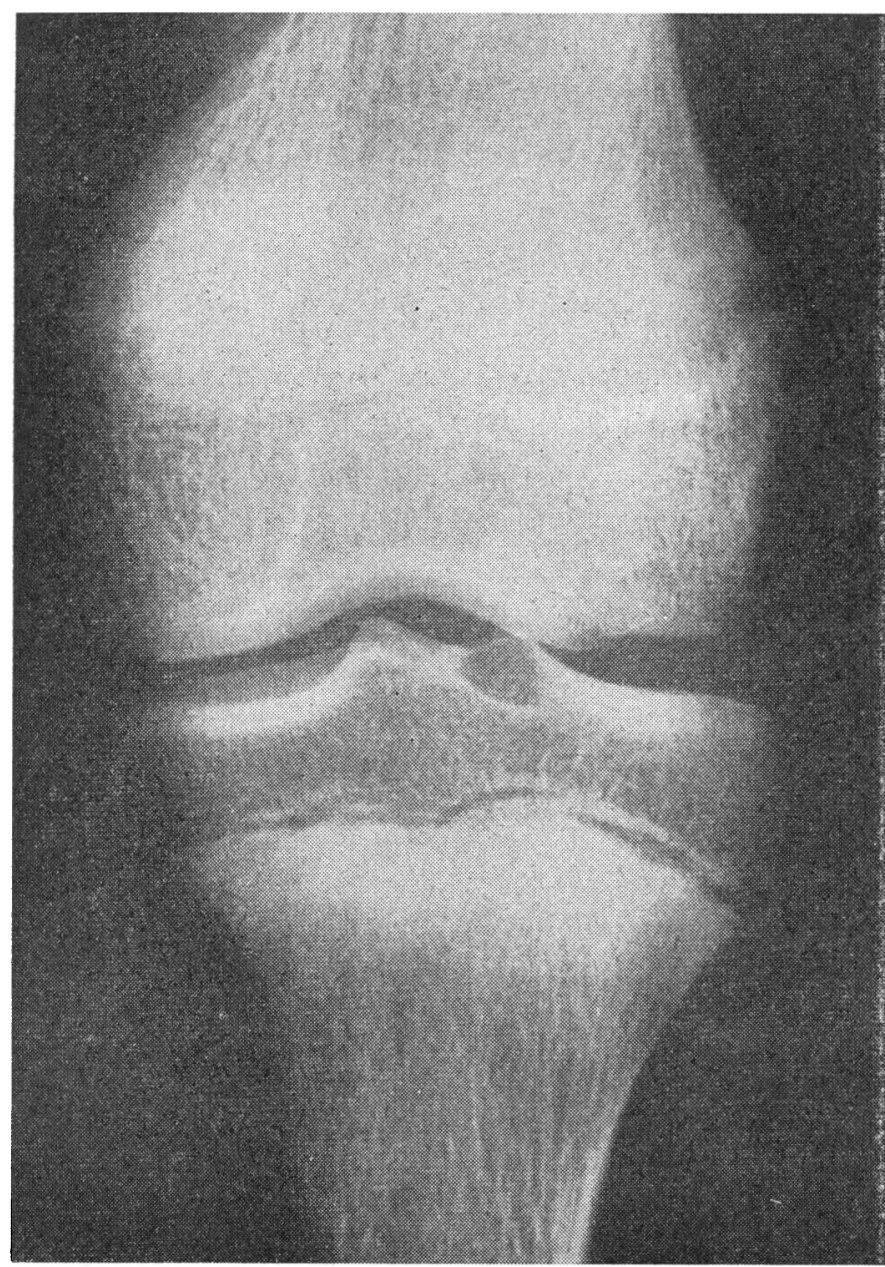

FIG. 4.-Radiolucent zone in femoral metaphysis; osteosclerosis in tibial metaphysis. some improvement in the degree of knock-knee, but bilateral femoral osteotomies were thought to be necessary. At the first osteotomy on 9 June bone from the lower end of the femur showed less fibrosis than the previous biopsy specimen of the iliac crest, few inactive osteoclasts, and decreased osteoblastic activity, now only slightly above normal for his age. Since his parathyroidectomy the patient had noticed limitation of forward and lateral flexion of his neck. Radiographs revealed a slight anterior displacement of the fifth on the sixth cervical vertebra, which may have been caused by extension of the neck during the operation.

An electroencephalogram on the tenth day after operation showed that the alpha ryhthm frequency had increased to 10 c.p.s., and, while there was still excessive bilateral temporal theta activity, its mean frequency had increased from 4-5 c.p.s. to 5-6 c.p.s. A further electroencephalogram seven months after operation showed bilaterally symmetrical alpha rhythm at $9 \frac{1}{2}-10$ c.p.s., with much less bilateral temporal activity at 5-6 c.p.s. than previously.

The serum alkaline phosphatase reached 101 King-Armstrong units/100 ml. 10 days after parathyroidectomy, and had fallen to 43 units four weeks later. Urinary hydroxyproline excretion fell post-operatively (see Table) and then increased to $385 \mathrm{~m}$./day one month after operation, remaining thereafter at similar levels at estimations up to four months later. The serum uric acid level was $6.3 \mathrm{mg} . / 100 \mathrm{ml}$. six months after parathyroidectomy.

\section{Discussion}

In children primary hyperparathyroidism appears to cause bone disease in a greater proportion of cases than in adults. In a recent review of the literature Nolan, Hayles, and Woolner (1960) noted that 18 out of 22 reported cases showed radiological evidence of bone disease. Renal calculi were present in only six cases, and five of these showed evidence of bone disease as well. Osteitis fibrosa cystica without abnormality of the epiphysial plate is the predominant type of bone disease in children, but rachitic changes have been described (Duken, 1928 ; Brailsford, 1953 ; Wood, George, and Robinson, 1958) and " condensation" of bone or osteosclerosis has also been reported (Dresser, 1933 ; Mimpriss and Butler, 1933-4 ; Albright, Baird, Cope, and Bloomberg, 1934 ; Shallow and Fry, 1948 ; Adam and Ritchie, 1954). The patient described by Duken (1928) was remarkably similar to ours in that knock-knee, beading of the ribs, metaphysial changes resembling rickets, osteosclerosis in the proximal tibial metaphyses, and subperiosteal erosions were all present. Renal function was normal and a diagnosis of primary hyperparathyroidism is acceptable, although parathyroidectomy was not performed. In our patient the occurrence of various types of

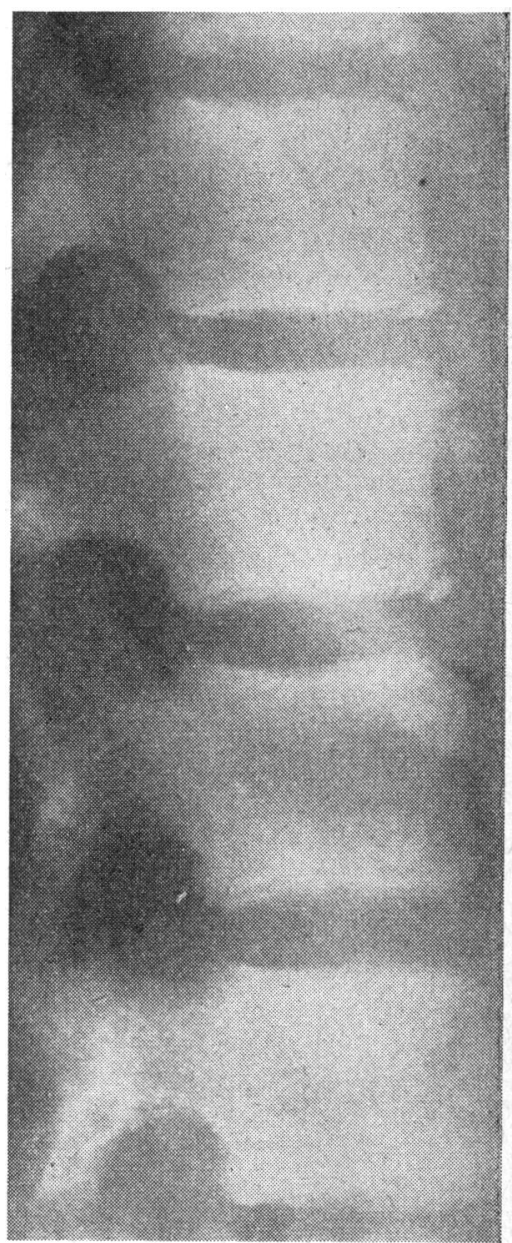

FIG. 5.-Osteosclerosis in upper and lower parts of vertebral bodies. 
osseous lesions, including vertebral osteosclerosis, raised the question of associated renal-glomerular osteodystrophy, but renal function was only slightly impaired, and, on the evidence of the blood urea, recovered quickly after removal of the parathyroid adenoma. That all the components of the bone disease had resulted from primary hyperparathyroidism is suggested by their healing after the operation.

The occurrence of osteosclerosis in primary hyperparathyroidism has been discussed elsewhere (Aitken, Kerr, and Lloyd, 1964). In the vertebrae it may take the form of "subchondral condensation" (Jaffe, 1933), or it may resemble the osteoselerosis of renal glomerular osteodystrophy, in which case the patients reported have had either associated chronic renal failure (Beveridge, Vaughan, and Walters, 1959 ; Wills, Richardson, and Paul, 1961) or steatorrhoea (Davies, Dent, and Willcox, 1956). Two children whose cases have been reported may have resembled our patient in having primary hyperparathyroidism and vertebral osteosclerosis without chronic renal failure, but data on their renal function are incomplete (Dresser, 1933 ; Albright, Baird, Cope, and Bloomberg, 1934). Osteosclerosis in the proximal tibial metaphyses has bcen described in children with primary hyperparathyroidism (Mimpriss and Butler, 1933-4; Adam and Ritchie, 1954), and appears to be a manifestation of the disease occurring during growth.

The nature of the radiolucent metaphysial lesions in our patient was unfortunately not established by histological examination. Bone from the iliac crest revealed changes of hyperparathyroidism, and among these the considerable increase in osteoblastic activity suggests that a true rachitic process might possibly have developed. However, it is of particular interest that the radiolucent zones in the distal femoral metaphyses were just proximal to the epiphysial plates, which did not appear to be enlarged. The radiolucent metaphysial lesions here and elsewhere may represent fibrous replacement of the bone as part of the process of osteitis fibro:a. Experiments described by Shelling (1935) indicate that metaphysial bone in young animals is especially sensitive to the effects of parathyroid hormone. Using different experimental procedures, Shelling was able to produce various changes in the metaphyses of young rats, including lesionts grossly resembling rickets but histologically characterized by fibrosis and osteoclastic proliferation in the subcartilaginous zone. In other experiments metaphysial osteosclerosis resulted. In an infant of 4 months with primary hyperparathyroidism Philips (1948) found fibrosis of the distal femoral metaphysis, increased numbers of osteoblasts, and, at the epiphysial line, irregularity of the cartilaginous trabeculae and uneven calcification. The evidence suggests, therefore, that in our patient the lesions simulating rickets consisted of osteitis fibrosa occurring in young metaphysial bone.

Increased hydroxyproline excretion is found in primary hyperparathyroidism with overt bone disease (Klein, Albertsen, and Curtiss, 1962 ; Dull and Henneman, 1963 ; Lee and Lloyd, 1964). Growing children excrete larger quantities than adults (Ziff, Kibrick, Dresner, and Gribetz, 1956), and during growth in adolescence excretion may range from 100 to $700 \mathrm{mg}$./day (Jones, Bergman, Kittner, and Pigman, 1964). Hence, in our patient rapid growth as well as bone disease probably accounted for the level of urinary hydroxyproline. The high rate of metabolic processes in bone in children as evidenced by urinary hydroxyproline excretion may have a bearing on the greater relative incidence of bone disease in children with p.imary hyperparathyroidism than in adults. Immature bone undergoing increased turnover of its collagen and other constituents may be more susceptible to the effects of increased parathyroid secretion than mature bone.

Nolan et al. (1960) drew attention to the high levels of serum calcium in children with primary hyperparathyroidism. Our patient survived, without apparent ill effects, a serum calcium of $19.2 \mathrm{mg} . / 100 \mathrm{ml}$. just before his operation, a rise of $3.3 \mathrm{mg} . /$
$100 \mathrm{ml}$. from the day before. Routine restriction of fluid intake pre-operatively may have precipitated this rise. Gordan (19612) has emphasized the risks of restricting fluid intake for the performance of urine-concentration tests in hypercalcaemic patients.

Neuropsychiatric disorders in primary hyperparathyroidism were the subject of a review by Karpati and Frame (1964). Whereas muscle weakness and hypotonicity are well-recognized features of the disease, choreic movements are not mentioned by these authors. There are very few reports of electroencephalographic studies in primary hyperparathyroidism. Slowing of electrical activity (Edwards and Daum, 1959) and right temporal dysrhythmia (Harmon, 1956) have been described. The tracings in our patient indicated a non-specific dysfunction of the upper brain stem which returned progressively to normal after operation.

Apart from the persisting limitation of flexion of the neck, the patient has made an excellent recovery with no evidence of permanent neurological or renal damage. The results of osteotomy of the left femur have been satisfactory. The deformity of the right lower limb is improving spontaneously, and further osteotomy may not be necessary. Considerable though slow improvement in severe knock-knee from primary hyperparathyroidism occurred without orthopaedic surgery in a patient reported by McClure and Lam (1945).

\section{Summary}

A case of primary hyperparathyroidism in a boy of 14 years is reported. The principal clinical features were knock-knee, mental apathy, and a neurological disturbance resembling chorea. Radiographs revealed osteitis fibrosa cystica, osteosclerosis, and metaphysial lesions resembling rickets.

We are indebted to Dr. J. Gallagher for the orthopaedic management of the patient, to Dr. M. J. Eadie for advice on the neurological aspects, and to Dr. N. G. Johnston for histological reports.

\section{REFERENCES}

Adam, A., and Ritchie, D. (1954). 7. Bone ft Surg., 36B, 257 Aitken, R. E., Kerr, J. F., and Lloyd, H. M. (1964).' Amer. F. Med., 37, 813.

Albright, F., Baird, P. C., Cope, O., and Bloomberg, E. (1934). Amer. F. med.. Sci., 187, 49.

Anspach, W. E., and Clifton, W. M. (1939). Amer. F. Dis. Child., 58, 540 .

Beveridge, B., Vaughan, B. F., and Walters, M. N. I. (1959). F. Fac. Radiol. (Lond.), 10, 197.

Brailsford, J. F. (1953). The Radiology of Bones and foints, 5:h ed., p. 108. Churchill, London.

Davies, D. R., Dent, C. E., and Willcox, A. (1956). Brit. med. F., 2, 1133.

Dresser, R. (1933). Amer. F. Roentgenol., 30, 596.

Dull, T. A., and Henneman, P. H. (1963). New Engl. F. Med., 268, 132.

Duken, J. (1928). Z. Kinderheilk., 46, 114.

Edwards, G. A., and Daum, S. M. (1959). Arch. intern. Med., 104, 29. Gordan, G. S. (1961-2). Year Book of Endocrinology, p. 38. Year Book Medical Publishers, Chicago.

Harmon, M. (1956). Amer. F. Dis. Child., 91, 313.

Jeffe, H. L. (1933). Arch. Path., 16, 63.

Jones, C. R., Bergman, M. W., Kittner, P. J., and Pigman, W. W. (1964). Proc. Soc. exp. Biol. (N.Y.), 115, 85.

Karpati, G., and Frame, B. (1964). Arch. Neurol. (Chic.), 10, 387.

Klein, L., Albertsen, K., and Curiss, P. H., jun. (1962). Metabolism, 11, 1023.

Lee, C. A., and Lloyd, H. M. (1964). Med. F. Aust., 1, 992.

McClure, R. D., and Lam, C. R. (1945). Ann. Surg., 121, 454

Mimpriss, T. W., and Butler, R. W. (1933-4). Brit. ... Surg., 21, 500.

Nolan. R. B., Hayles, A. B., and Woolner, L. B. (1960). Amer. F. Dis. Child., 99, 622.

Philips. R.' N.'(1948). Pediatrics, 2, 428.

Prockop, D. J., and Udenfriend, S. (1960). Analyt. Biorhem., 1, 228

Shallow, T. A., and Fry, K. E. (1948). Surgery, 24, 1020.

Shelling, D. H. (1935). The Parathyroids in Health and Disease, p. 100. Kimpton, London.

Wills, M. R., Richardson, R. E., and Paul, R. G. (1961). Brit. med. F., i, 252.

Wood. B. S. B., George, W. H., and Robinson, A. W. (1958). Arch. Dis. Childh.. 33, 46

Ziff, M., Kilbrick, A., Dresner, E., and Gribetz, H. J. (1956). f. clin. Invest., 35, 579 . 